\title{
Gross Anatomy of the Nose, Nasal Cavity and Larynx in the Pampas Deer (Ozotoceros bezoarticus, Linnaeus 1758)
}

\author{
Noelia Vazquez ${ }^{1}$, Horst Erich König ${ }^{2}$, Hassen Jerbi ${ }^{3}$, William Pérez ${ }^{1}$ \\ ${ }^{1}$ Área de Anatomía, Facultad de Veterinaria, Universidad de la República, Lasplaces 1620, 11600 Montevideo, \\ Uruguay \\ ${ }^{2}$ InstitutfürAnatomie, Histologie und Embryologie, VeterinärmedizinischeUniversität Wien, Veterinärplatz 1, \\ A-1210 Wien, Austria \\ ${ }^{3}$ Service d'Anatomie, EcoleVéterinaireSidiThabet. CP 2020, Tunisie
}

\begin{abstract}
Available information on the anatomy of the respiratory system of the pampas deer (Ozotoceros bezoarticus, Linnaeus 1758) is scarce, so the aim of this work was to describe the upper respiratory tract anatomy of this species. The study was performed with 10 adult animals of both sexes and the study method was simple dissection. Pampas deer had a nasolabial plane different to the small domestic ruminants. The nasal cavity had the fundamental conformation of the ruminants with simple winding of the dorsal concha and double winding of the ventral one. The vomeronasal organ communicated directly with the oral cavity by the incisive duct. The larynx was located ventrally to the first two cervical vertebrae. The total length of the larynx was $52.76 \pm 7.66 \mathrm{~mm}$ from the epiglottis to the cricoid cartilage. The dorsoventral length was $30.32 \pm 3.71 \mathrm{~mm}$. It is necessary to make detailed histological examinations of the distribution of the olfactory epithelium versus non-sensory epithelium within the nasal cavity. These data are essential to understand the function of the turbinates and the nasal cavity in general. In the same way, detailed studies of the physiology of the vomeronasal organ and larynx are necessary.
\end{abstract}

Keywords: Cervidae; Deers; Respiratory System; Ruminant.

\section{Introduction}

The pampas deer (Ozotocerosbezoarticus, Linnaeus, 1758) was a widespread species, originally distributed in the open grasslands (pampas) across eastern South America, from $5^{\circ}$ to $41^{\circ} \mathrm{S}$ (Jackson and Langguth, 1987). However, the number of animals and populations declined during the last two centuries due to the loss of habitat, unregulated hunting, competition with cattle (Jackson and Giullieti, 1988), and transmission of cattle diseases (Jungius, 1976). There are small populations remaining in Argentina, Brazil and Uruguay, butthe species is considered as near threatened by IUCN (González and Merino 2008).In Uruguay, there are two endemic subspecies (González et al., 1998; 2002):O. b. arerunguaensis (Salto, $31^{\circ} 65^{\prime} \mathrm{S}, 56^{\circ} 43^{\prime} \mathrm{W}$ ) and O. b.

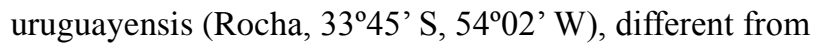
the O. b. bezoarticus, O. b. leucogaster, and O. b. celer previously described (Jackson and Langguth, 1987).

In previous studies in this spececieswe described the papillaes of the tongue by scanning electron microscopy, the gross anatomy of the gastrointestinal tract and its arterial vascularization (Pérez et al., 2008; Pérez and Ungerfeld, 2012; Erdoğan and Pérez, 2013; Pérez et al., 2017) and reproductive organs (Pérez et al., 2013 a, b). Other of our studies were related to the arterial supply involve the distribution of the aortic arch (Perez and Erdôgan, 2014), the adrenal gland (Erdôgan and Pérez, 2014), gastrointestinal (Pérez et al., 2016) and pelvis with pelvic limbs (Vazquez et al., 2018).

Most scientific knowledge about the anatomy of the respiratory apparatus of domestic ruminants is documented in a vast number of publications and in classic textbooks (Nickel et al., 1987; Saber, 1983; Barone, 2010; König and

Copyright (C) 2018 Noelia Vazquez et al.

doi: 10.24294/as.vli2.617

EnPress Publisher LLC.This work is licensed under the Creative Commons Attribution-NonCommercial 4.0 International License (CC BY-NC 4.0). http://creativecommons.org/licenses/ by/4.0 
Liebich, 2015). In deer, Bisaillon (1985) studied the larynx in white-tailed deer and more recently Frey et al. have performed physiological work in relation to vocalization in other ruminants (Frey et al., 2003, 2006, 2007a, b). Frey's works initiated a path to correlate the anatomy of the organ with its phonation function. This author investigates the anatomy of the organ of phonation and acoustic behavior during the reproductive season in Ruminants such as red deer.

Our current knowledge of the respiratory system anatomy of non-domestic ruminants is based only in some descriptions about few of the near to 300 extant species. The information on the respiratory system of the pampas deer is null. The anatomical information obtained is interesting for future physiological or clinical studies that have been carried out in a similar way in other ruminant species (Frey et al., 2003, 2006, 2007a, b, Stierschneider et al., 2007). In this study we described the anatomy of the nose, nasal cavity and larynx, in order to increase the anatomical knowledge of these species.

\section{Materials and Methods}

In Uruguay, there is a population of pampas deer maintained in semicaptive conditions in a native fauna breeding station (Estación de Cría de Fauna Autóctona

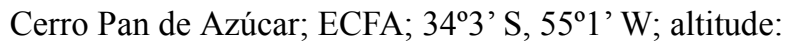
$\sim 200 \mathrm{~m}$ ) (Ungerfeld et al., 2008). This population was originated in 1982 from O. b. arerunguaensis animals, and actually consists of approximately 80 animals. Ten animals ( 7 females and 3 males) that were found dead at the ECFA from causes unrelated to the respiratorytract,and were frozen until dissection, were used. The specimens were handled and treated according to the local Ethical Board guidelines of Universidad de la República (Uruguay).

The main method of study of the animals was simple macroscopic dissection. Pictures were taken with a Nikon digital camera.Terms were used in agreement with the NominaAnatomicaVeterinaria (2017).

\section{Results}

The bony support of the nose and the nasal cavity was formed dorsally by the nasal bones, laterally by the maxillary bones and ventrally by the palatine processes of the incisive, maxillary and palatine bones, that formed the osseous support of the hard palate. The palatine bone occupied almost half of the surface, extending caudally from the first molar. The ethmoid and the vomer are also involved in the constitution of the nasal cavity next to the nasal conchae (Figure 12).

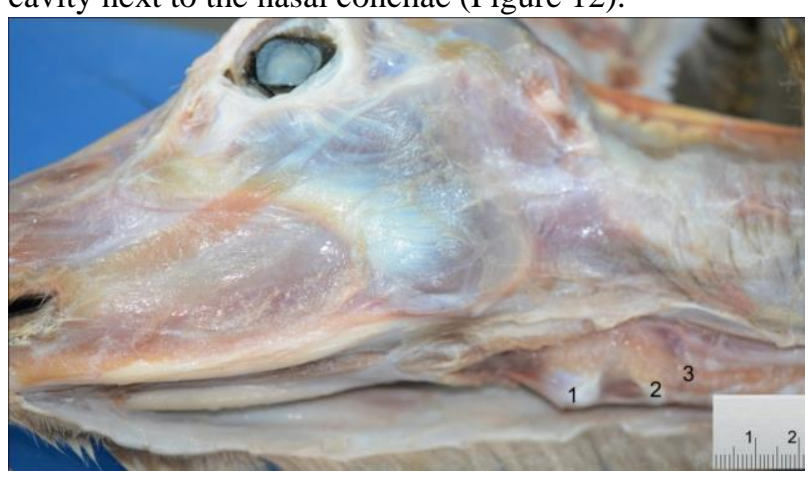

Figure 12; Left side view of the head of a female pampas deer after removal of the skin. 1: Laryngeal prominence; 2: Cricoid cartilage; 3: Trachea.

The upper lip had a little marked filter and in its medial parts it entered into the constitution of a pigmented nasolabial plane, black in all the animals. The philtrum divided the nasal plane. The surface of the nasolabial plane was subdivided into small irregular areas by shallow grooves. The dorsal part of the nasolabial plane that was located between the nostrils was smooth. The lateral parts of the upper lip on its outer face were white.

The nasal cavity itself began rostrally with the nasal vestibule. The nasal vestibule was always pigmented in black and continued caudally with the nasal cavity without a clear delimitation in the limit of the nose (Limen nasi). On the nasal vestibule and near to the limit of the nose we had the location of the nasolacrimal ostium, the terminal orifice of the duct of the same name.

The nasal cartilages were rostral to the nasal osseous opening formed by the nasal, incisive, and maxillary bones, and served as a support base for the nostril and nasal vestibule. The nasal vestibule was complemented by the mobile part of the nasal septum. These cartilages were mobilized by muscles that were involved in controlling the amount of air inhaled. We had the presence of the alar cartilage, the lateral dorsal and lateral ventral cartilages and the lateral and medial accessory nasal cartilages.

The movements of the nostrils and nasal vestibule were given by muscles that were inserted into the 
bones and skin of the neighborhood. These were the dilator of the nostrils, the canine, and the nasolabial levator.

The nasal cavity, ended caudally in the choanae, openings on both sides of the nasal septum. This cavity was separated by the bony palate from the mouth and was elongated as the face. The median nasal septum (Figure 2) divided the nasal cavity into two symmetrical halves. The nasal cavity was described as a right half and a left half and each one had a roof, a floor, two walls (medial and lateral), and two extremities.

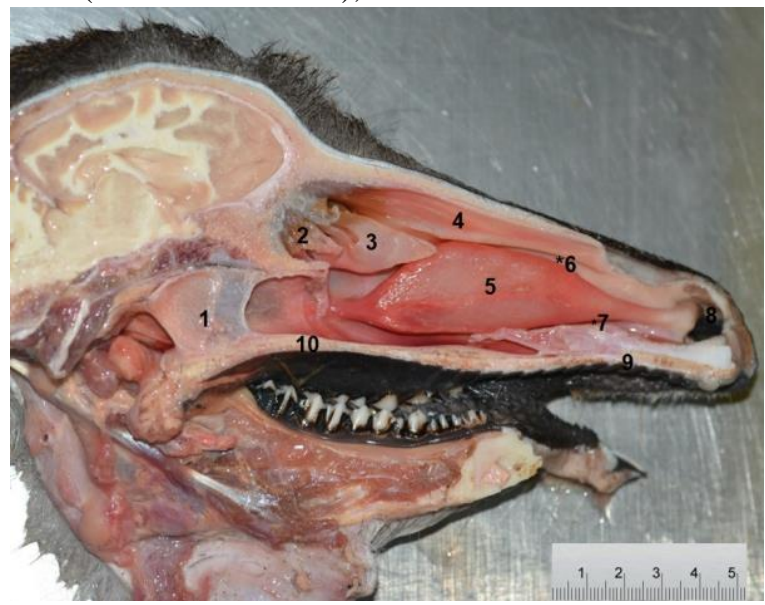

Figure 2; Sagittal section of the head of the pampasdeer, medial view of the lefthalf 1: Nasopharynx; 2: Ethmoidalconchae; 3: Middle nasal concha; 4: Dorsal nasal concha; 5 : Ventral nasal concha; 6: Middlemeatus; 7: Ventral meatus; 8: Nostrils; 9: Hardpalate; 10: Soft palate.

The roof of the nasal cavity was a longitudinal leak under the lateral dorsal cartilage and nasal bone to the roof of the ethmoidal labyrinth (Figures 3, 4, 7).

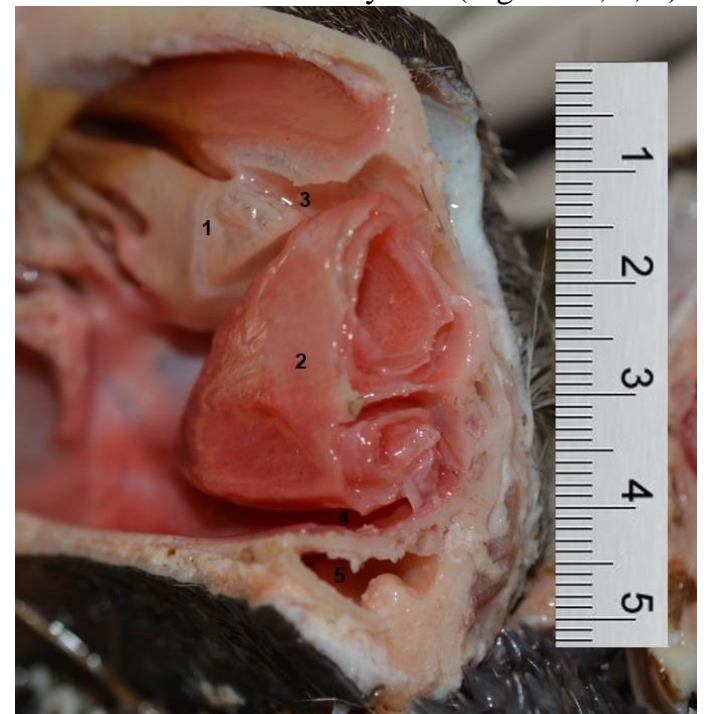

Figure 3; Cross section of the nasal cavity, rostrocaudal and medial view of the left side.1: Middle nasal concha; 2: Ventralnasal concha; 3: Middle meatus; 4: Ventral meatus; 5: Palatine sinus.

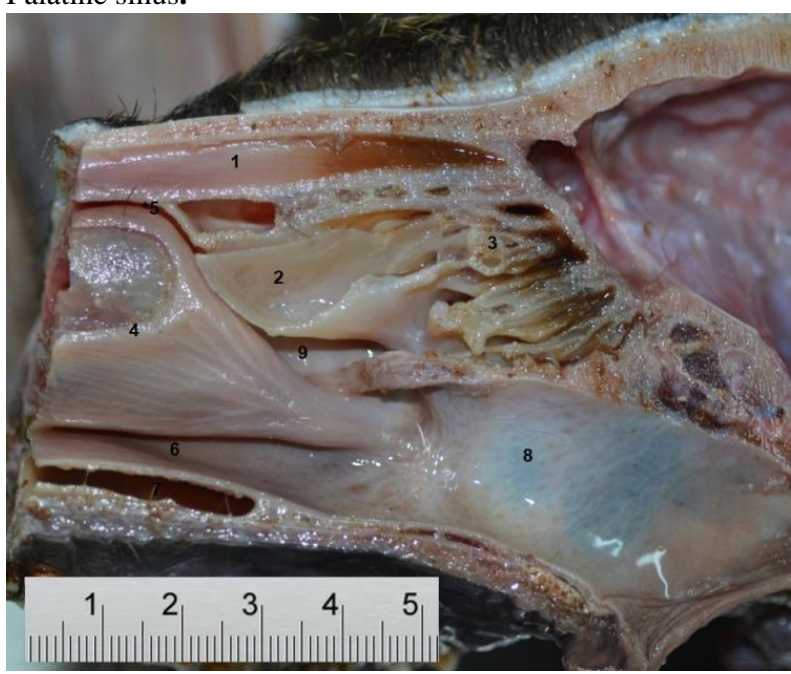

Figure 4; Cross section of the nasal cavity of pampas deer, caudal view.1: Dorsal nasal concha; 2: Middle nasal concha; 3: Ethmoidal concha; 4: Ventral nasal concha; 5, 9:

Middle meatus; 6: Ventral meatus; 8: Nasopharynx.

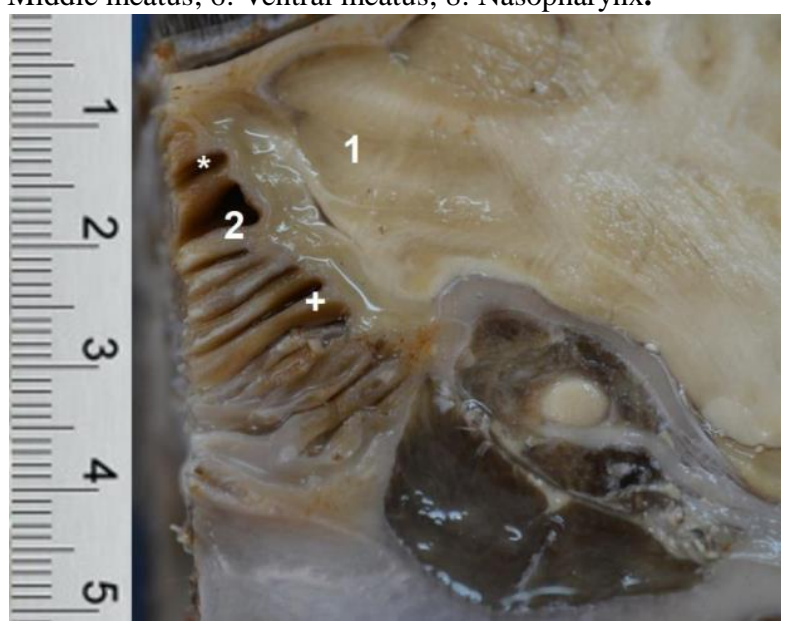

Figure 7; Sagittal section of the caudal half of the pampas deer head, medial view of the left side.1: Olfactory bulb; 2: Conchae and ethmoidal meatos; *: Meatos; +: Conchae.

The floor was wider than the roof, carried by the palate.

The rostral tip joined the nasal vestibule at the limit of the nose and the caudal extremity presented caudally in its dorsal part the ethmoidal labyrinth formed by the ethmoidal turbinates. The ventral part of this extremity was the nasopharyngeal meatus, which communicated with the opposite side because the nasal septum did not reach the caudal part of the cavity.

The medial wall belonged to the septum was ver- 
tical and flat. The nasal septum began rostrally with a mobile cartilaginous part and had a ventral and caudal bony part. It was fixed to the palatine process of the incisive bone, the vomer and the perpendicular lamina of the ethmoid.

The lateral wall was oblique ventrolaterally, very irregular and anfractuous, showed the protuberance of the conchae. There were two groups of conchae, one rostral and one caudal. The rostral group was that of the dorsal and ventral nasal conchae (Figure 2, 3, 4, 5, $6,8,9,10)$. The middle nasal concha was the most developed of the ethmoid turbinates that advanced cranially (Figures 2, 3, 4).

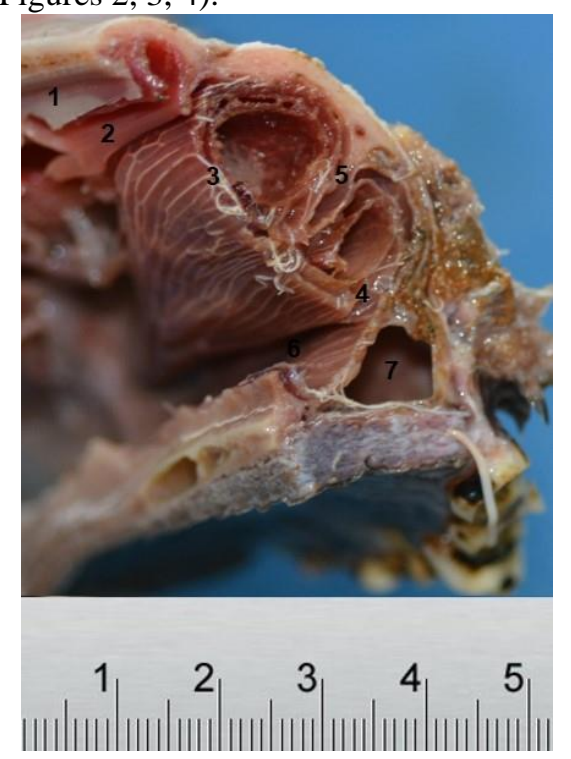

Figure 5; Cross section of the nasal cavity of pampas deer, rostral view.1: Nasal septum; 2: Dorsal nasal concha; 3: Dorsal lamina of the ventral concha; 4: Ventral lamina of the ventral concha; 5: Main lamina of the ventral concha; 6 : ventral meatus; 7: Palatine sinus

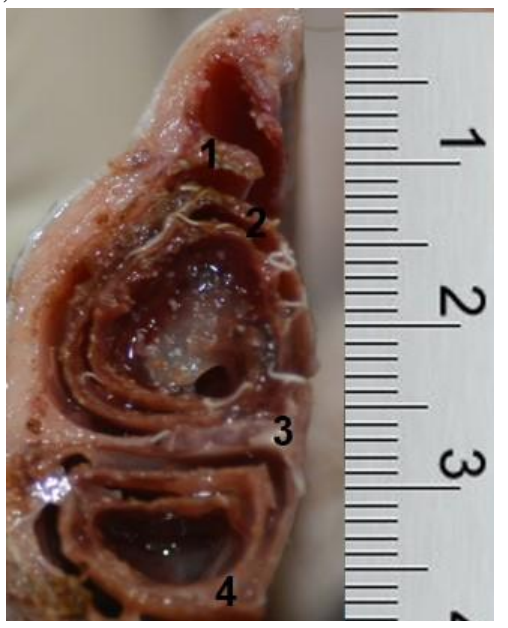

Figure 6; Cross section of the nasal cavity of pampas deer, rostral view.1: Dorsal nasal concha; 2: Dorsal lamina of the ventral concha; 3 : Main lamina of the ventral concha; 4 : Ventral lamina of the ventral concha.

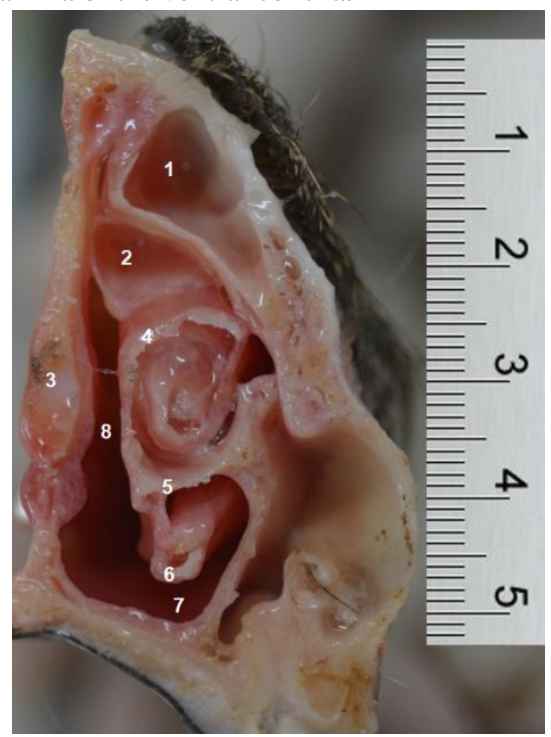

Figure 8; Cross section of the nasal cavity of pampasdeer, frontal view.1: Maxillarysinus; 2: Dorsal nasal concha; 3: Septum nasal 4: Dorsal lamina of the ventral concha; 5: Mainlamina of the ventral concha; 6: Ventral lamina of the ventral concha; 7: Ventral meatus; 8: Commonmeatus.

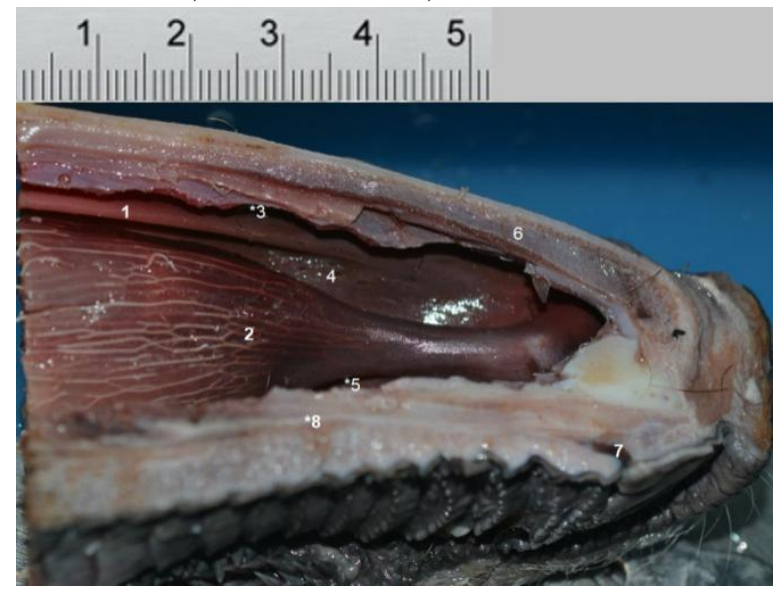

Figure 9; Sagittal section of the rostral part of the nasal cavity, medial view of the left side.1: Dorsal nasal concha; 2 : Ventral concha with superficial blood vessels; 3 : Dorsal meatus; 4: Middle meatus; 5: Ventral meatus; 6: Nasal septum; 7: Incisive duct;8: Vomeronasal organ. 


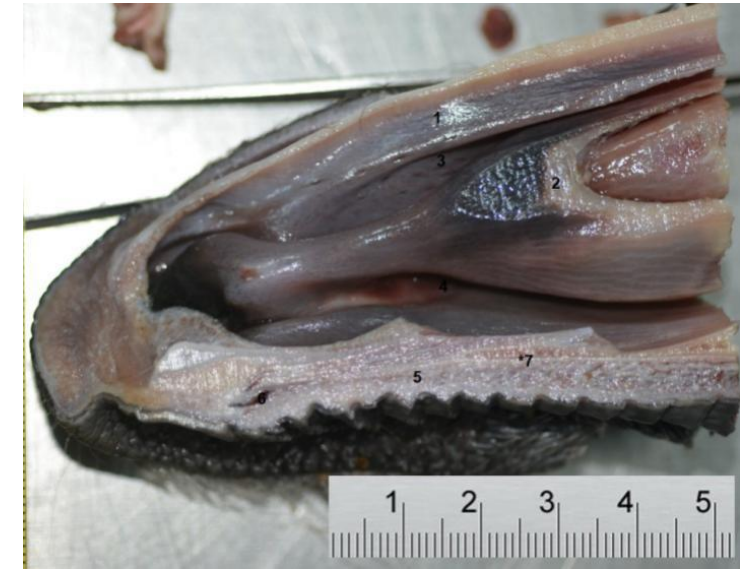

Figure 10; Sagittal section of the rostral part of the nasal cavity, medial view of the right side.1: Dorsal nasal concha; 2 : Ventral nasal concha; 3: Middle meatus; 4: Ventral meatus; 5: Hard palate; 6: Incisive duct; 7: Vomeronasal organ.

The dorsal concha was simple (Figures 1, 2, 4, 5, 6 ), had a dorsal turbinate sinus and was attached caudally to the lamina papyraceaof the ethmoid and extended rostrally into a cartilaginous part called rectus fold.

The ventral concha, also called maxilloturbinate (Figures 1, 2, 3, 4, 5, 6, 8), was inserted over the conchal crest of the maxillary bone and was more developed than its dorsal counterpart. It had a double curl, a main lamina fixed to the maxilla that was divided into dorsal and ventral laminae (Figures 1, 2, 5, 6, 8). The caudal limb of the ventral lamina was simple and did not form a ventral conchal sinus. This turbinate was continued with two cartilaginous extensions, the alar and basal folds.

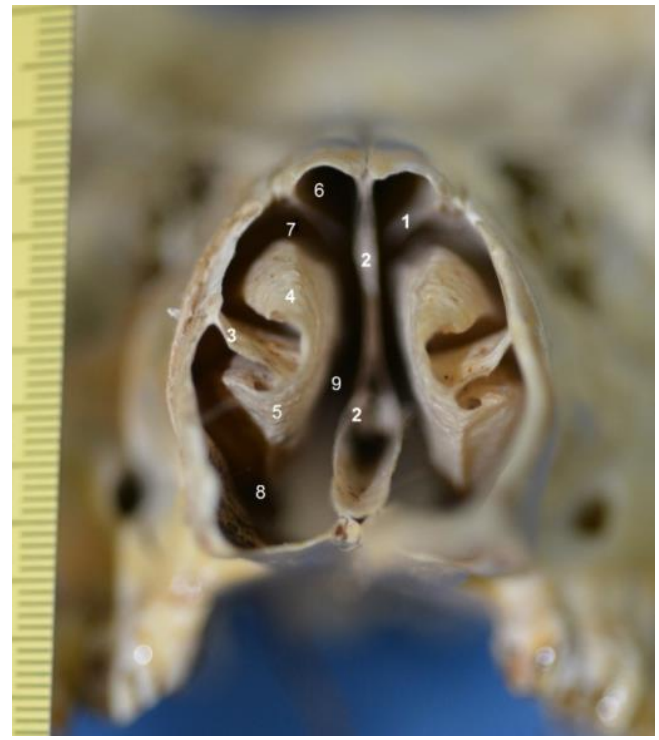

Figure 1; Rostral view of the skull (nasal cavity) of the pampas deer.1: Dorsalnasal concha; 2: Nasal septum; 3: Main lamina of the ventral concha; 4 : Dorsal lamina of the ventral concha; 5: Ventral lamina of the ventral concha; 6: Dorsal meatus; 7: Middle meatus; 8: Ventral meatus; 9: Common meatus.

The middle nasal concha was the first and largest volute of the ethmoid or endoturbinated (Figures 2, 3, 4). There were no mucous folds associated with this turbinate.The ethmoid turbinates (Figures 2, 4, 7) that formed the ethmoidal labyrinth were formed by the scrolls of the ethmoid and covered by olfactory mucosa. The scrolls of the ethmoid or ethmoturbinated (Ethmoturbinalia) were divided into two groups, the ectoturbinados and the endoturbinates. The endoturbinates were only visible in the sagittal section of the head that passed near the septum, to which the middle turbinate belonged. The ethmoid turbinates were separated by the narrow ethmoid meatos (Figure 7) that were the spaces between them. These were finished caudally in a cul-de-sac against the lamina cribosa of the ethmoid.

There were on each side of the nasal cavity four nasal passages or meatus: dorsal nasal meatus, middle nasal meatus, ventral nasal meatus and common nasal meatus. These meatus were presented as longitudinal depressions between the conchae (Figures 1, 2, 3, 4, 8).

The relatively narrow dorsal nasal meatus (Figures $1,9,10)$ ran through the dorsal nasal concha and terminated caudally on the cribriform plate of the ethmoid. Its roof was formed by the nasal bone in its rostral section and the frontal in the caudal part. The dorsal nasal meatus was regularly in open communication with the common nasal meatus.

The narrow middle nasal meatus (Figures1, 4, 9, 10) was situated between the dorsal and ventral nasal conchae. The dorsal spiral lamina of the ventral concha and the spiral lamina of the dorsal conchawere partially overlapped and narrowed the middle nasal meatus. The middle nasal meatus was divided caudally into a dorsal and ventral part by the middle nasal concha. The ventral part of the middle nasal meatus was continued towards the nasopharynx in the ventral part of the ethmoidal labyrinth, ventrally to which the ventral nasal concha ended.

The spacious ventral nasal meatus (Figures1, 3, 4, 8, 9, 
10) was delimited dorsally by the alar fold and the basal lamina of the ventral nasal concha. The floor of the nasal cavity formed its ventral termination. The ventral nasal meatus flowed caudally to the nasopharynx.

The common nasal meatus (Figures 1, 8), formed between the roof of the nasal cavity and the floor of the nasal cavity, on the one hand, and between the nasal septum and the nasal conchae, on the other hand, had its greatest width at the level of the ventral spiral lamina of the ventral nasal concha.

The vomeronasal organ of the pampas deer was located ventrally on the floor of the nasal cavity, laterally to the surface of the nasal septum (Figures 9, 10). The organ itself was contained in an envelope of cartilage (Cartilagovomeronasale) that extends from approximately the rostral part of the palatine bone to the incisive canal. The organ communicated with the oral cavity through the incisive canal, finally opening on each side of the incisive papilla (Figures 17, 18).

The paranasal sinuses found in the pampas deer were the frontal, maxillary, palatine and lacrimal (Figures 9, 10). They were small and poorly developed.

It is necessary to consider that these sinuses communicated with the nasal cavity and there weresinuses in the dorsal and middle nasal conchae, but not in the ventral one.

The larynx of Ozotoceros bezoarticus was located cranially in the neck ventrally to the first two cervical vertebrae, suspended to the hyoid bone and joined to the pharynx and beginning of the esophagus (Figures $11,12,15)$. Considered as a whole, the larynx was elongated in cranio - caudal direction, wider dorsally than ventrally where the laryngeal prominence ended up protruding.

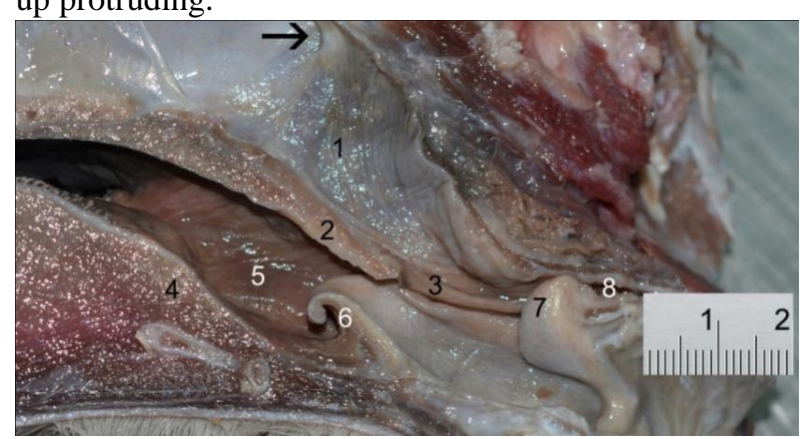

Figure 11. Medial view of the right half of the pharynx and larynx of the pampas deer after median section of the head. 1: Nasopharynx; 2: Soft palate; 3: Palatopharyngeal arch; 4: Root of the tongue; 5: Oropharynx; 6: Epiglotis; 7: Corniculatedprocessof the arytenoid cartilage; 8: Esophagus

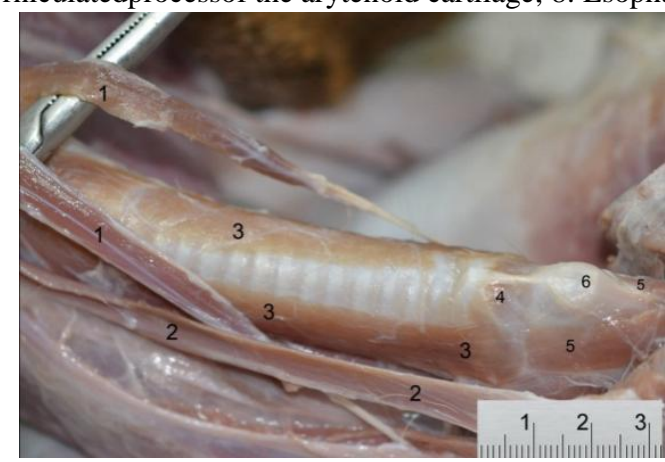

Figure 15; Left ventrolateral view of the neck region. 1: Sternobasilar portion of the sternocephalic muscle; 2: Sternomandibular portion of the sternocephalic muscle; 3: Sternothyroid muscle; 4: Crichothyroid muscle; 5: Thyrohyoid muscle; 6: Laryngeal prominence.

The total length of the larynx was $52.76 \pm 7.66$ $\mathrm{mm}$ from the epiglottis to the caudal edge of the cricoid cartilage. The dorsoventral length was $30.32 \pm 3.71$ mm (Figures 13, 14).

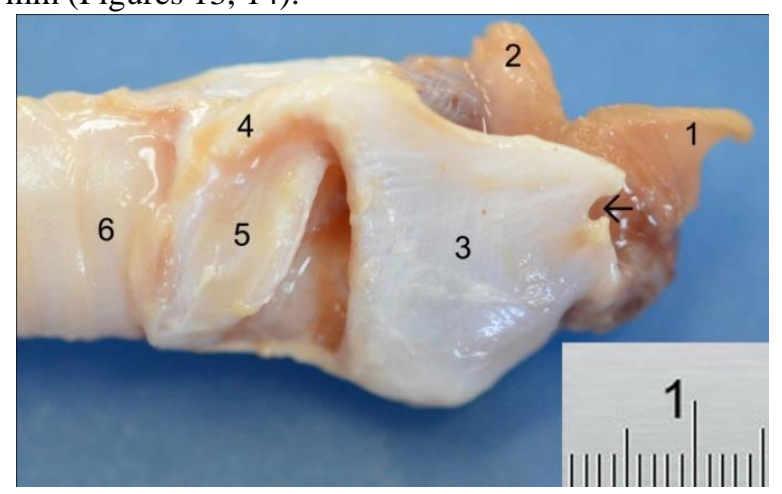

Figure 13; Right side view of the larynx of the female pampas deer. The muscles, vessels and nerves were removed. 1: Epiglottis; 2: Corniculated process of the arytenoid cartilage; 3: Thyroid cartilage; 4: Caudal horn of the thyroid cartilage; 5: Cricoid cartilage; 6: Trachea. $\rightarrow$ : Thyroid fissure.

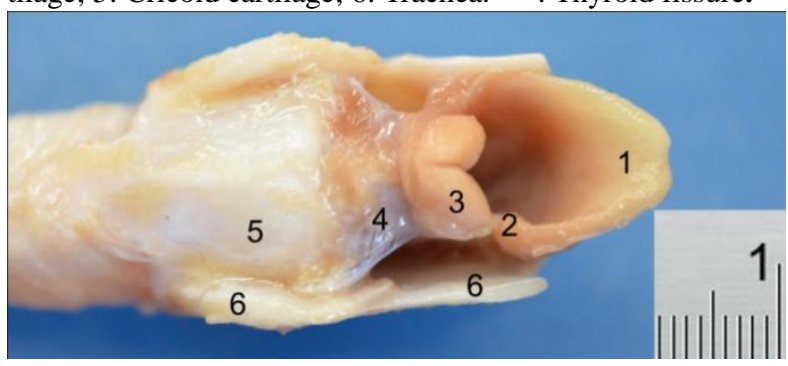

Figure 14; Dorsal view of the larynx of the female pampas deer. 1: Epiglottis; 2: Ariepiglotic fold; 3: Corniculated process of the arytenoid cartilage; 4: Transverse arytenoid muscle; 5: Cricoid cartilage; 6: Thyroid cartilage.

The larynx was formed by three umpair cartilages: 
the cricoid, the thyroid and the epiglottis, and an even cartilage: the arytenoid. There were no accessory cartilages. The thyroid, cricoids and arytenoidscartilages without the corniculated processes were of hyaline cartilage, while the epiglottis and the corniculated processes of the arytenoids were of elastic cartilage.

The largest cartilage of the larynx was the thyroid, odd and symmetrical, consisted in two convex and irregular laminae fused in the midline (Figures 4, 5, 6). The thyroid cartilage was cranial to the cricoid cartilage, caudal to the epiglottis and laterally to the arytenoid cartilages (Figures 12, 13, 14, 15). Both side plates of the thyroid cartilage were smooth laterally, formed a large part of the lateral wall of the larynx and at their median junction formed the laryngeal prominence, which was undeveloped and tuber-shaped (Prominentialaryngea) (Figures 12, 15). This prominence was equally prominent in both sexes.

It was related dorsally to the base of the epiglottic cartilage, which adhered to the laryngeal prominence by the tiroepiglottic ligament, which was elastic, thick and strong. There was a rostral horn in the thyroid cartilage and a thyroid fissure, where the cranial laryngeal nerve entered, which was distributed to the mucosa of the organ (Figure 13). The caudal horn was very long (Figure 13).

The cricoid cartilage hadtypically the form of a signet ring and was rostral to the first tracheal cartilaginous ring and caudodorsally to the thyroid cartilages (Figures 13, 14). The cricoid cartilage had caudally articular surfaces for the thyroid, and articular surfaces in the rostral part of the lamina to the arytenoid cartilage. The caudal edge of the cricoid was thin and was joined to the first tracheal ring by the cricotracheal ligament. The internal surface was very soft and covered by the respiratory mucosa.

The arytenoid cartilages were irregular with pyramidal shape and were located rostrally to the cricoid cartilage and a little dorsally to the thyroid cartilages (Figures 11, 13, 14). The corniculated processes of the arytenoid cartilage (Figures11, 13, 14) were formed by elastic cartilage and the rest of the cartilage was hyaline.

The epiglottis cartilage had an elongated leaf shape and was located cranially and medially to the thyroid cartilages (Figures 11, 13, 14). The lingual surface of the epiglottis was concave from the apex to the base while the laryngeal surface was very elongated and planiform. There were no cuneiform cartilages. In all the animals studied, the epiglottis was located ventrally to the soft palate, which was visualized in the medium cuts made in the corpses (Figure 11).

The cartilages of the larynx were joined together and to the hyoid bone by two types of joints, synovium and syndesmosis. The synovial joints were the cricothyroid and the cricoarytenoid joints. The cricothyroid joint joined the corresponding lateral facet of the cricoid cartilage to the caudal horn of the thyroid cartilage and the synovium was reduced. The cricothyroid ligament extended between the cricothyroid joints closing ventrolaterally the space between the cricoid and thyroid cartilages. The arytenoid cartilages are joined together by a small transverse arytenoid ligament, which is covered dorsally by the small transverse arytenoid muscle. The cricoarytenoid joint is very small and synovial. The union of the arytenoids to the thyroid is given by the vocal fold. Finally, the base of the epiglottis was attached to the thyroid by a thyroepiglottic ligament.

The larynx was attached to the hyoid bone at the thyrohyoid joint, which links the thyrohyoid to the rostral horn of the thyroid cartilage. This joint is fibrous, without a synovium. The cricotracheal ligament joined the thyroid cartilage to the first ring of the trachea, was broad and elastic.

The extrinsic muscles of the larynx were poorly developed and represented by the thyrohyoid, sternothyroid and hyoepiglottic muscles (Figure 15). There was no sternohyoid muscle. The width of the thyrohyoid muscle in its middle part was $9.69 \pm 1.37 \mathrm{~mm}$. The width of the sternothyroid muscle in the vicinity of its termination on the thyroid cartilage was $9.85 \pm 1.33$ $\mathrm{mm}$. The hyoepiglottic muscle was very small. The intrinsic muscles of the larynx were: cricothyroid, dorsal cricoarytenoid, lateral cricoarytenoid, transverse arytenoid, and thyroarytenoid. The lateral cricoarytenoidwas hidden by the laminae of the thyroid cartilage and were very little developed.

The Adituslaryngiswas $25.98 \pm 9.5 \mathrm{~mm}$ long and $11.1 \pm 3.09 \mathrm{~mm}$ wide, and its edge was formed ceane- 
oventrally by the epiglottis, laterally by the ariepiglottic folds and dorsocaudally by the corniculated process of the arytenoid cartilage (Figures 11, 14 ). The thickness of the ariepiglottic folds was $1.93 \pm 0.93 \mathrm{~mm}$. The thickness of the corniculated processes of the arytenoid cartilage was $4.46 \pm 0.9 \mathrm{~mm}$.

The laryngopharynx or laryngeal part of the pharynx extended between the base of the epiglottis and the beginning of the esophagus, ventrally to the intrapharyngeal ostium. Between the epiglotticvallecula (Valleculaepiglottica) and the beginning of the esophagus, two deep grooves, the piriform recesses, were extended (Figure 15).

The laryngeal cavity was connected rostrally with the laryngopharynx and caudally with the tracheal cavity (Figures. 11, 13). Three parts, the vestibule or supraglottic part, the glottis and the infraglottic part formed this cavity. There was a median depression in the floor of the vestibule of the larynx, rostral to the union of the vocal folds: the medial recess of the larynx (Recessuslaryngismedianus). 10). The glottis, a narrow central part of the laryngeal cavity, had the usual two parts, intercartilaginous dorsal between the arytenoid cartilages and ventral intermembranous between the vocal folds (Plica vocalis), forming a central rhombic structure. The length of the vocal fold was $14.8 \pm 3.25$ and its width was $3.84 \pm 0.46 \mathrm{~mm}$.

The supraglottic part is wider, limited rostroventrally by the epiglottis,dorsocaudally by the arytenoid cartilages and laterally by the ariepiglottic folds.

The length of the infraglottic part of the larynx was $16.01 \pm 2.77 \mathrm{~mm}$. It was broad and short, with no caudal demarcation, composed mainly of the cricoid cartilage and the cricothyroid ligament.

Unlike the nasopharynx and oropharynx, there were no tonsils in the laryngopharynx, or paraepiglottic tonsils (Tonsillaparaepiglottica).

The caudal part of the laryngopharynx that gave rise to the esophagus corresponded to the esophagus vestibule (Vestibulumoesophagi) and was located in front of the cricoid cartilage.The ventral part of the laryngopharynx was occupied by the long entrance of the larynx (Adituslaryngis).

The irrigation of the larynx and its muscles was mainly given by two direct branches of the common carotid artery, the cranial and caudal laryngeal arteries. The veins were mostly satellites.

The cranial and caudal laryngeal nerves, branches of the $\mathrm{X}$ cranial nerve or vagus nerve, gave the innervation of the larynx. The cranial laryngeal nerve had only one internal branch that was distributed to the mucosa of the organ and entered through the cranial thyroid incisura. The recurrent laryngeal nerve proceeded from the thorax and accompanied the trachea dorsolaterally, and when it reached the larynx with the name of caudal laryngeal nerve it was distributed mainly to the intrinsic muscles.

\section{Discussion}

According to our knowledge, this is the first whole anatomical description of the nasal cavity and larynx in a deer species. This is particularly importantfor pampas deer considering the conservation status of this species. One limitation for vets and surgeons of zoo animals and wildlife is the scarce information available on the anatomy of these species, increasing the risks during any treatment due to possible inadequate approaches.Therefore, having available basic anatomical knowledge of anatomyis very important for different applications.

The nasal cavity of mammals is an intricate anatomical structure with a variety of shapes, sizes and functional roles. The "fundamental conformation" of the nasal cavity remains relatively consistent in most mammals (Moore, 1981) and in fact the same happens in the pampas deer. The nasal conchae help to present an irregular and winding route for air flow during inhalation. As the inspired air travels through the airways, the increased surface area (partly thanks to the turbinates arrangement) fulfills multiple functions such as air conditioning, filtration of contaminants, smell and conservation of heat and water (Negus, 1958; Schmidt-Nielsen et al., 1970; Moore, 1981).

The most rostral portion of the nasal cavity, the nasal vestibule is the main responsible for the filtration and transport of inspired air to the respiratory region. Due to the lack of appreciable vasculature, very little conditioning of the inspired air occurs in the nasal vestibule, which is lined with squamous epithelium (Craven et al., 2007, Harkema et al., 2006, Negus, 1958, Reznik, 1990 ). Continuing, the air flows caudally 
through the respiratory region of the nasal cavity, where the conchae extend from the lateral walls.

Conchae complexity tends to vary depending on the lifestyle and functional needs of the species (Van Valkenburgh et al., 2011), with the more complex arrangement typically found in Ungulates and Carnivores (Negus, 1958, Van Valkenburgh et al. , 2014). The increasing order of complexity in turbinates includes: simple winding, double winding and branching (Negus, 1958, Craven and others, 2007, Van Valkenburgh et al., 2014). For the case of pampasdeer we have a simple winding for the dorsal turbinate and a double winding for the ventral turbinate. This is the same as found in domestic ruminants (Barone, 2010)

The maxilloturbinate or ventral concha of white-tailed deer is approximately $50 \%$ of the total length of the nasal cavity (Ranslow et al., 2014), like in pampas deer. Although the deers had a much simple ventral concha than in the carnivores, the structure is extended by a greater distance in order to increase the surface area. The length of a concha can compensate for the lack of complexity as seen with the extended, but simple, double spiral winding of these deer species.

In the olfactory region, etmoturbed complexes also present a large surface area to increase the deposition of odoriferous substances that come with the air flow. Etmoturbinets play the main role in smell (Craven et al., 2010). These turbinates are present in varying degrees in most adult mammals, with the exception of some cetaceans in which olfactory structures are reduced or lost (Berta et al., 2014).

In animals with high olfactory capacity (macrostatic) (eg, rodents, carnivores, ungulates), the dorsal meatus directly connects the olfactory region with the nasal vestibule, providing a way for the airflow to elude the respiratory region during inspiration (Craven et al., 2007, Craven et al., 2010; Lawson et al., 2012; Ranslow et al., 2014).

Ranslow et al. (2014) showed that the white-tailed deer has simple ventral turbinates, but very complex etmoturbinates compared to carnivores. The white-tailed deer has bent moths that are more intricate than those of other animal moths, which, as observed by Ranslow et al. (2014), provides a larger surface for smelling in a compact space.
The vomeronasal organ is a very important structure and in the pampas deer it communicates directly with the oral cavity by the incisive canal. The vomeronasal organ was described in detail in the sheep by Kratzing (1971). It is reported that flehmen occur much more frequently in deer during the mating season than in other occasions (Muller-Schwarze, 1979). This organ is used as a final determinant for the recognition of offspring during lactation in sheep (Booth, 2006). Even in sheep, sexual dimorphism has been described in this organ, being somewhat larger in males (Khosravinia and Abbasi, 2014). It is neccesary make physiological studies of this organ in pampas deer.

In mammals, the great diversity of habitats and social systems has led to the evolution of a great variety of vocal tract specializations. Some studies (Bisaillon, 1985, Frey and Gebler, 2003, Frey et al., 2006, Frey et al., 2007a, b) have been carried out to date showing that the anatomical and physiological aspects of the larynx in the wild animals. These studies have demonstrated functional characteristics and explanations of the mechanisms of vocalization (Harrison, 1980, Frey and Gebler, 2003, Frey et al., 2006; Frey et al., 2007a, b) and the taste buds of the larynx (Bradley et al., 1980; Yamamoto et al., 2001).

The larynx of pampas deer was located cranially in the neck, ventrally to the first 2 cervical vertebrae. This location varies with the degree of flexion and extension of the neck in the different species, its caudal edge reaches the fourth cervical vertebra in the pig, in equines it is found in the intermandibular space (Barone, 2010). The descending larynx has been used to differentiate the human from other animal species where the larynx is closer to the oral cavity (Fitch and Reby, 2001). The descending larynx has been described in the Mongolian gazelle (Frey and Gebler, 2003), in the red deer stag (Cervuselaphus) and in the male stag deer (Damadama) (Fitch and Reby, 2001). In these species the larynx can be retracted during vocalization which lengthens the vocal tract and allows the roar that the males emit.

It is composed of the same cartilages as domestic ruminants, lacking cuneiform cartilages. In contrast to many ruminants, it was reported that the width of the laminae of the thyroid cartilage was greater than its 
length, acquiring a triangular shape (in the camel of a hump (Saber, 1983)). The caudal horn of the thyroid cartilage was 2.5 times longer than the rostral horn in musk ox (Frey et al., 2006), and the rostral horn was relatively smaller in the reindeer (Frey et al., 2007a). As in Ozotoceros, the rostrodorsal angle of the lamina was extended to form the short straight rostral horn and the thyroid fissure was a deep notch between the rostral horn and the rostral edge of the thyroid lamina in the cow and sheep (Getty, 1975 ) and the white-tailed deer (Bisaillon, 1985). Through this fissure the cranial laryngeal nerve in these species and in Ozotoceros entered into the larynx. The caudal horn was similar to that of domestic ruminants (Getty, 1975), musk ox (Frey et al., 2006) and reindeer (Frey et al., 2007a). In the white-tailed deer (Bisaillon, 1985), the caudal horn was shorter, but thicker than its rostral counterpart. The laryngeal prominence is underdeveloped just like domestic ruminants.

Cricoid cartilage is the typical signet ring in many domestic and wild mammals (Getty, 1975, Hast, 1979, Bisaillon, 1985, Frey et al., 2006, Frey et al., 2007a, b, Barone, 2010). In Ozotoceros, the same form of cricoid cartilage was observed. It was not indented in its lower part like the ox. The rostral edge of the lamina had the same thickness as the caudal margin, on the contrary of the Ox and the white-tailed deer where the rostral edge is wider (Basaillon, 1985).

The epiglottic cartilage was shaped like an elongated leaf in Ozotoceros. Likewise, it has the shape of a vaulted leaf on the sheep and the ox, and like a cordate leaf on the goat (Barone, 2010). Like white-tailed deer and ruminants, the ariepiglottic fold is strong and fuses with its counterpart on the dorsal surface of the arytenoid cartilages.

On the other hand, there was no cuneiform cartilage of the epiglottis in Ozotoceros. Likewise, the absence of cuneiform cartilages, caudally directed and located on both sides of the epiglottis, was reported in the cat, sheep, goat and cattle (Getty, 1975, Hast, 1979, Guintard, 2005, Barone, 2010). On the other hand, the cuneiform cartilage is present in the dog, the horse (Getty, 1975, Niquel, 1987) and the Mongolian gazelle (Frey and Gebler, 2003).

The arytenoid cartilages were similar to those of the sheep (Getty, 1975, Goulden, 2002, Barone, 2010). The corniculated processes were joined by their base to the apex of the arytenoid and curved cartilages dorsally and medially curved in ruminants and horse, as in Ozotoceros (Barone, 2010).

Ozotoceros was devoid of a ventricle of the larynx. This ventricle is present in horses, pigs, dogs and to a lesser extent in the rabbit (Barone, 2010). In its place there is only a weak depression in domestic ruminants (Barone, 2010). The laryngeal ventricle is homologous to the exit air larynx (Saccuslaryngis) of the primates that descends caudally in the neck, even to the axillary region in the orangutan (Hayama, 1970).

The anatomy of the larynx and vocalization was studied in the musk ox (Frey et al 2006). This species forms harems and access to females is given by spectacular agonist encounters between males with the association of a very marked male roar during periods of heat. The roar in adult females is given more for communication with the child. This species presents a marked sexual dimorphism in the anatomy of the head, but not in the larynx, where the region of the glottis is thicker in the male. They are provided with an ventrorostral odd ventricle in the larynx that is inflated with air during the initial phase of the roar, which can give more amplitude and a serious timbre to the roar acting as a resonance chamber. Ozotoceros bezoarticus had no laryngeal ventricle similar to that described in the musk ox.

In the saiga antelope (Saigatatarica) the nose is involved in vocal production, producing nasal grunts (Frey et al., 2007b). This animal also fights for the possession of 5 to 50 females. Also have been described particularities in the vocal folds of this species (Frey et al., 2007b).

The Mongolian gazelle (Procapragutturosa) also has a lowered larynx, a wide epiglottis, a great development of the laryngeal muscles and the presence of highly developed laryngeal ventricles (Frey and Gebler, 2003). In this species the competition between males for reproduction is vigorous.

The reindeer and the caribou (which are of the same species: Rangifer tarandus) that have polygamous mating system, a male creates a group of 20 to 100 females with fighting between males (Frey et al., 
2007a). These animals are characterized by characteristic vocalizations called grunts in the males that also occur in the female to communicate with the child. The vocal tract of the reindeer has evolved to a peculiar specialization, the laryngeal air sac, being the only species described of cervid to possess it (Frey et al., 2007a). This structure that emerges from the laryngeal vestibule increases the amplitude of vocalization according to these authors.

In animals that have a mating system by harem, few males have the majority of females, therefore the vocalization helped by the laryngeal sac can reduce the number of fights between males by acoustic rejection and by attraction of the females, being very advantageous (Frey et al., 2007a).

Therefore, the mating system seems to be related to snarling or growling-type vocalizations, being more noticeable in polygamous species that form harems, a situation contrary to what happens in Ozotoceros bezoarticus (Ungerfeld et al., 2008b).The joints and muscles of the larynx of Ozotoceros bezoarticus were similar to those of domestic ruminants. Regarding the innervation of the organ, the main difference found was that the cranial laryngeal nerve did not emit a branch for the cricothyroid muscle, which does happen in domestic ruminants (Barone, 2010).

We need detailed histological examinations of the distribution of the olfactory epithelium versus non-sensory epithelium within the nose. These data are essential to understand the function of the turbinates and the nasal cavity in general. In the same way detailed studies of the physiology of the vomeronasal organ and larynx (especially related to vocalization) are necessary.

\section{Acknowledgements}

We thank to IntendenciaDepartamental de Maldonado (IDM) for the facilities to develop research with the animals of the ECFA, and CSIC (Universidad de la República) and IDM for financial support.

\section{References}

1. Barone R. Anatomiecomparée des mammifèresdomestiques, Splanchnologie Fœtus et ses Annexes. AppareilDigestif - AppareilRespiratoire. Vigot. France [in French]. Anatomicalcomparison of domestic mammals, Splanchnology Fetus and its Appendices. DeviceDigestive - Respiratory Device. Vigot. La France 2010.

2. Berta A, Ekdale EG, Cranford TW. Review of the cetacean nose: Form, function, and evolution. The Anatomical Record 2014; 297(11):2205-2215.

3. Bisaillon A. The larynx of the white-tailed deer. ActaTheriol 1985; 30:139-148.

4. Booth KK. The significance of the vomeronasal organ for offspring recognition in sheep. Small Rumin Res 2006; 62:39-41.

5. Bradley RM, Cheal ML, Kim YH. Quantitative analysis of developing epiglottal taste buds in sheep. J Anat 1980; 130:25-32.

6. Casteleyn C, Breugelmans S, Simoens P, et al. The tonsils revisited: Review of the anatomical localization and histological characteristics of the tonsils of domestic and laboratory animals. Clin Dev Immunol 2011, ID472460, 14p.

7. Cosse M, Gonzálezand S, Gimenez-Dixon M. Feeding ecology of Ozotocerosbezoarticus: Conservation implications in Uruguay Iheringia. Ser. 2009; Zool.99:158-164.

8. Cocquyt G, Baten T, Simoens P, et al. Anatomical localisation and histology of the ovine tonsils. Vet Immunol. Immunopathol 2005; 107:79-86.

9. Craven BA, Neuberger T, Paterson EG, et al. Reconstruction and morphometric analysis of the nasal airway of the dog (Canisfamiliaris) and implications regarding olfactory airflow. Anat Rec 2007; 290:1325-1340.

10. Craven BA, Paterson, EG, Settles GS. The fluid dynamics of canine olfaction: unique nasal airflow patterns as an explanation of macrosmia. Journal of the Royal Society, Interface / the Royal Society 2010; 7:933-943.

11. Eiting TP, Smith TD, Perot JB, et al. The role of the olfactory recess in olfactory airflow. $\mathrm{J}$ ExpBiol 2014; 217:1799-1803.

12. Erdoğan S, Pérez W. Anatomical and scanning electron microscopic characteristics of the tongue in the pampas deer (Cervidae: Ozotocerosbezoarticus, Linnaeus 1758). Microsc. Res Tech 2013; 76:1025-1034.

13. Fitch WT, Reby D. The descended larynx is not uniquely human. Proceedings of the Royal Society of London. Series B: Biological Sciences 2001; 268:1669-1675.

14. Frey R, Gebler A. The highly specialized vocal tract of the male Mongolian gazelle (Procapragutturosa Pallas, 1777--Mammalia, Bovidae). J Anat 2003; 203:451-471.

15. Frey R, Gebler A, Fritsch G. Arctic roars - laryngeal anatomy and vocalization of the muskox (Ovibosmoschatus Zimmermann 1780, Bovidae). J Zool 2006; 268:433-448.

16. Frey R, Gebler A, Fritsch G. Nordic rattle: The hoarse vocalization and the inflatable laryngeal air sac of reindeer (Rangifer tarandus). J Anat 
2007a; 210:131-59.

17. Frey R, Volodin I, Volodina E. A nose that roars: Anatomical specializations and behavioural features of rutting male saiga. J Anat 2007b; 211:717-736.

18. Gaughan EM, Hackett RP. Ducharme ND. Clinical evaluation of laryngeal sensation in horses. Cornell Vet 1990; 80:27-34.

19. Getty R, Sisson, Grossman's. The anatomy of the domestic animals. 5th edn. W. B. Saunders, Philadelphia, USA. 1975; Vol. 1.

20. González S, Álvarez-Valin F, Maldonado J. Morphometric differentiation of endangered pampas deer (Ozotocerosbezoarticus), with description of new subspecies from Uruguay. J. Mammal 2002; 83:1127-1140.

21. González S, Maldonado JE, Leonard JA, et al. Conservation genetics of the endangered Pampas deer (Ozotocerosbezoarticus). Mol. Ecol 1998; 7:47-56.

22. González S, Alvarez F, Maldonado JE. Morphometric differentiation of the endangered pampas deer (Ozotocerosbezoarticus L. 1758). J.Mammal 2002; 83:1127-1140.

23. Gonzalez S, Merino ML. Ozotocerosbezoarticus. In: The IUCN Red List of Threatened Species. Version 2014. 3. . Downloaded on 15 March 2018.

24. Goulden BE. The equine larynx. New Zeal Vet J 2002; 50:117.

25. Guintard C. Comparative anatomy of the larynx in domestic mammals: Conformation and topography. Biom Human Anthropol 2005; 23:73-81.

26. Nomina AnatomicaVeterinaria. International Committee on Veterinary Gross Anatomical Nomenclature (I.C.V.G.A.N.) 6 thed. Available at http://www.wava-amav.org/downloads/nav_6_20 17. zipDownloaded on 15 march 2018.

27. Harkema JR, Carey SA, Wagner JG. The nose revisited: A brief review of the comparative structure, function, and toxicologic pathology of the nasal epithelium. Toxicologic Pathology 2006; 34:252-269.

28. Harrison DF. Biomechanics of the giraffe larynx and trachea. Acta Otolaryngol 1980; 89:258-264.

29. Hast MH. Anatomy of the sheep larynx. J Anat 1979; 129: 854-855.

30. Hayama S. The saccuslaryngisin primates. J Anthropol Soc 1970; 78:274-298.

31. Jackson JE. Ozotocerosbezoarticus. Mamm. Species 1987; 295:1-5.

32. Jackson J, Langguth A. Ecology and status of pampas deer (Ozotocerosbezoarticus) in the Argentinian pampas and Uruguay. Biology and management of the Cervidae, Ed. C. Wemmer, Smithsonian Institution Press, Washington, DC 1987; 402-409.

33. Jackson J, Giullieti J. The food habits of pampas deer Ozotocerosbezoarticusceler in relation to its conservation in relict natural grassland in Argentina. Biol Conserv 1988; 45:1-10.

34. Jungius H. Status and distribution of threatened deer species in South America. World Wildlife Yearbook. World Wildlife Fund. Morges, Switzerland 1976; 203-217.

35. Kingdon J. East African Mammals: An Atlas of Evolution in Africa, Part B: Large Mammals. University of Chicago Press, USA 1988; (3):313-37.

36. Khosravinia H, Abbasi M. Sexual dimorphism in lori sheep vomeronasal organ dimensions and their relationships with external body measurements. Anim Res Int 2014; 11:1939-1045.

37. Kratzing JE. AN. The structure of the vomeronasal organ in the sheep. J. Anat 1971; 108(Pt 2), 247.

38. König HE, Liebich H-G. Anatomie der Haussäugetiere. Lehrbuch und Farbatlasfür Studiumund Praxis. Online-Bilddatenbank. Schattauer. Stuttgart, Bundesrepublik Deutschland [in Germany]. Anatomy of domestic mammals. Textbook and color atlas for study and practice. Online image database. Schattauer. Stuttgart, Federal Republic of Germany 2015.

39. Lawson MJ, Craven BA, Paterson EG, et al. A computational study of odorant transport and deposition in the canine nasal cavity: Implications for olfaction. Chem Senses 2012; 37:553-566.

40. Menke C. Morphologie und topographischeAnatomie der Nase, der Nasenhöhlesowie der Nasennebenhöhlen und assoziiertenStrukturenbeimEuropäischenMufflon (Ovisgmelinimusimon Pallas 1811). Tesis: TierärzlicheHochschule Hannover [in Gemany]. Morphology and topographical anatomy of the nose, nasal cavity, paranasal sinuses and associated structures in European mouflon (Ovisgmelinimus Simon Pallas 1811). Tesis: TierärzlicheHochschule Hannover. 2003; 143p.

41. Moore WJ. The Mammalian Skull. Cambridge: Cambridge University Press, 1981. 369.

42. Mueller-Schwarze D. Flehmen in the context of mammalian urine communication. Chemical ecology: Odour communication in animals, Elsevier/North Holland Biomedical Press, Amsterdam, 1979. 85-96.

43. Negus VE. The comparative anatomy and physiology of the nose and paranasal sinuses. London: Livingstone, 1958.

44. Nickel R, Schummer A, Seiferle E. Lehrbuch der Anatomie der Haustiere. 6. Aufl [in Germany]. Textbook of the Anatomy of Pets. 6th edition. Berlin, Paul Parey, 1987. Vol. 2.

45. Pérez W, Claussand M, Ungerfeld R. Observations on the macroscopic anatomy of the intestinal tract and its mesenteric folds in the pampas deer (Ozotocerosbezoarticus). Anat.Histol.Embryol 2008; 37:317-321. 
46. Pérez W, Ungerfeld R. Gross anatomy of the stomach of the pampas deer, Ozotocerosbezoarticus (Artiodactyla: Cervidae). Zoologia. 2012; 29:337-342.

47. Pérez W, Vazquez N, Ungerfeld R. Gross anatomy of the female genital organs of the pampas deer (Ozotocerosbezoarticus, Linnaeus 1758). Anat.Histol.Embryol 2013a; 42:168-174.

48. Pérez W, Vazquez N, Ungerfeld R. Gross anatomy of the male genital organs of the pampas deer (Ozotocerosbezoarticus, Linnaeus 1758). Anat.Sci.Int 2013b; 88:123-129.

49. Pérez W, Erdoğan S. Arterial ThoracicVascularization in SomeDeerSpecies: Pampas Deer (Ozotoceros bezoarticus), Brown BrocketDeer (Mazamagouazoubira) and Axis Deer (Axis axis). Anat. Histol. Embryol. 2014; 43:490-494.

50. Pérez W, Vazquez N, Ungerfeld R.Arterial Vascularization of the Gastrointestinal Tract of the Pampas Deer (Ozotocerosbezoarticus, Linnaeus, 1758). Anat. Histol. Embryol 2016; 45:240-245.

51. Ranslow AN, Richter JP, Neuberger T, et al. Reconstruction andmorphometricanalysisof the nasal airwayof the white-taileddeer (Odocoileusvirginianus) andimplicationsregardingrespiratoryandolfactory airflow. AnatRec (Hoboken) 2014; 297:2138-2147.

52. Reznik GK. Comparative Anatomy, Physiology, and Function of the Upper Respiratory Tract. Environ Health Perspect 1990; 85:171-176.

53. Saber AS. The cartilages of the larynxof the one-humpedcamel (Camelus dromedarius) and sheep (Ovis aries). Anat Histol Embryol 1983; 12:77-84.

54. Schmidt-Nielsen K, Hainsworth FR, Murrish DE. Counter-current heat exchange in the respiratory passages: effect on water and heat balance. Respirationphysiology 1970; 9(2):263-276.

55. Stierschneider M, Franz S, Baumgartner W. Endoscopicexaminationof the upper respiratory tract and oesophagus in smallruminants: Techniqueand normal appearance. 2007; Vet J173:101-108.

56. Ungerfeld R, González-Sierra UT, Piaggio J. Reproduction in a semi-captiveherd of pampas deer Ozotocerosbezoarticus. Wildlife Biol 2008; 14: 350-357.

57. Van Valkenburgh B, Smith TD, Craven BA. Tour of a labyrinth: exploring the vertebrate nose. Anat Rec 2014; 297:1975-1984.

58. Van Wieren SE. Digestive strategies in ruminantsand non ruminants. Land bouw universiteit Wageningen, Germany, 1996. 191.

59. Vazquez N, Ríos C, Sorriba V, et al. Arterial distributionto the pelviccavity and pelviclimb in the pampas deer (Ozotoceros bezoarticus, Linnaeus 1758). Anat Histol Embryol 2018; 47:133-139.

60. Weber M, González S. Latin American deer diversity and conservation: A review of status and distribution. Ecoscience 2003; 10:443-454.

61. Wemmer C. Deer: status survey and conservation action plan (IUCN/SSC Action plans for the conservation of biological diversity). World Conservation Union, Oxford, 1998. 112.

62. Yamamoto Y, Atoji Y, Hobo S. Morphology of the nerve endings in laryngeal mucosa of the horse. Equine Vet J 2001; 33:150-158. 